\title{
Erratum to: Differential somatostatin and CXCR4 chemokine receptor expression in MALT-type lymphoma of gastric and extragastric origin
}

\author{
Susann Stollberg ${ }^{1} \cdot$ Daniel Kaemmerer $^{2} \cdot$ Elisa Neubauer $^{1} \cdot$ Stefan Schulz $^{1} \cdot$ \\ Ingrid Simonitsch-Klupp ${ }^{3}$ Barbara Kiesewetter ${ }^{4} \cdot$ Markus Raderer $^{4} \cdot$ Amelie Lupp $^{1}$
}

Published online: 1 December 2016

(C) Springer-Verlag Berlin Heidelberg 2016

\section{Erratum to: J Cancer Res Clin Oncol (2016)}

142:2239-2247

DOI 10.1007/s00432-016-2220-6

The family name of one of the co-authors was incorrect in the original publication. The correct name should read as Daniel Kaemmerer.

The online version of the original article can be found under doi:10.1007/s00432-016-2220-6.

Amelie Lupp

Amelie.Lupp@med.uni-jena.de

1 Institute of Pharmacology and Toxicology, Jena University Hospital, Friedrich Schiller University Jena, Drackendorfer Str. 1, 07747 Jena, Germany

2 Department of General and Visceral Surgery, Zentralklinik Bad Berka, Bad Berka, Germany

3 Clinical Institute for Pathology, University of Vienna, Vienna, Austria

4 Department of Internal Medicine I, University of Vienna, Vienna, Austria 